\title{
NOTAS HISTÓRICAS SOBRE LA JUSTICIA GRATUITA EN ESPAÑA
}

\author{
INÉS PEDRAZ PENALVA
}

Profesora Agregada de Geografía e Historia I.B.

\section{SUMARIO.}

I 1 Introducción.

II 2. Delimitación del estudio.

3. Sobre la Justicia gratuita en los Ordenamientos históricos italiano y francés.

III 4. Configuración histórico-normativa de la Justicia gratuita en España.

5. Requisitos exigibles a las personas físicas para gozar del beneficio de pobreza.

6. Beneficios y limitaciones que implica el reconocimiento de la pobreza.

7. La pobreza de las personas jurídicas.

IV 8. A modo de colofón.

I.-1. Antes de entrar en lo que constituye el punto central de estas breves reflexiones históricas sobre el derecho a la Justicia gratuita, acaso conviniera esbozar, a muy grandes rasgos, la actual situación de este derecho de categoría constitucional.

La primera posición que ocupa en nuestro Ordenamiento Jurídico la Ley Fundamental es determinante a efectos del derecho básico de toda persona a la obtención de la tutela judicial efectiva, en defensa de sus derechos e intereses legítimos, sin que pueda sufrir indefensión (1). Pero tal Derecho Fundamental del art. 24,1 de la Constitución española, en su desarrollo por nuestro Tribunal Constitucional, comporta, singularmente, la exigencia de que se supriman cualesquiera obstáculos susceptibles de impedir la plena vigencia del citado Derecho del Art. $24 \mathrm{CE}$. Precisamente, el elevado coste de la Justicia es uno de los óbices capaces de convertir en ilusorio tal derecho de acceso a la Jurisdicción, motivo por el que el legislador constituyente proclamó,en el art. $119 \mathrm{CE}$, de manera especifica, que "La Justicia será gratuita cuando así lo disponga la Ley y, en todo caso, respecto de quienes acrediten insuficiendia de recursos para litigar".

Cabe citar a este respecto la actual plasmación del Derecho a la justicia gratuita en diversos Convenios internacionales, tales como el Pacto Internacional de Derechos Civiles y Políticos de New York, de 19 de Diciembre de 1966 (ratificado por España en 27 de Abril de 1977), en su artículo 14.3.d, el Convenio Europeo para la protección de los Derechos Humanos y de las Libertades Fundamentales, aprobado en Roma en 4 de Noviembre de 1950 (ratificado por España en 26 de septiembre de 1979), en su artículo 6.3.c, etc. 
Destacaré pues la regulación constitucional del derecho de acceso a la Justicia de todas las personas, sin que puedan sufrir discriminación por razón de insuficiencia de medios económicos, lo que, además, vulneraría el principio de igualdad del artículo $14 \mathrm{CE}$ (2).

II.-2. Al hablar de la configuración histórica del derecho a la Justicia gratuita se pretende solamente ubicar el tema, sin ir más allá de lo dicho en el apartado anterior ni aludir a la regulación normativa vigente, lo que excedería tanto del objetivo propuesto como de la metodología y aparato conceptual precisos para ello. Esto, no osbatante, y según podrá comprobarse, he tenido que acudir por la propia entidad temática, a examinar de manera especial textos jurídicos, que son los que, lógicamente, acomenten la reglamentación del derecho a la justicia gratuita.

II.-3. La solución históricamente más radical -con una cierta pero esporádica continuidad- sobre la Justicia gratuita, se encuentra en la institución "iuscanonista" del "adbocatus pauperum deputatus et stipendiatus" (3). Este "advocatus pauperum..." constituía un oficio permanente, con deteminadas funciones y privilegios, susceptible de ser considerado en cierta medida, desde perspectivas actuales, como un "servicio público tendente a ejercer el patrocinio gratuito de los pobres" (4).

Distinto de tal instituto del Derecho canónico era la "abogacía de pobres", diferenciándose por FERRARIS (5) en cuanto que "est hoc expresse praeceptum a Paulo V... et hoc intellige ubi non repetitur deputatus et stipendiatus propios advocatus pauperum, quia, ubi adest ille... adest ille, non tenentur allii, cum ipse teneatur ex iustitia et officio, ratione stipendii et privilegiorum, et maxime privilegii fori, quo gaudet etiamsi sit laicus, ut declaravit sana congragatio inmunitatis in Beneventan a 20 Julii 1655". Por autores como CAPPELLETTI se ha llegado a decir que la realización de esta avanzada idea quedó en las buenas intenciones, lógicamente en cuanto se trataba de una tentativa ideológicamente prematura en una época feudal dotada de una organización político-social jerárquicamente desigual. (6).

La "Abogacía de pobres" aparece en Italia hacia fines del S. XIV en los Estados saboyanos e incluso en el XIII, en Parma (7). En Italia subsistió en el reino del Piamonte "una avvocatura dei poveri', con un ámbito de actuación verdaderamente muy limitado (8), extendida a todo el reino de Italia en un primer momento (Ley Ratazzi, de 13 de Noviembre de 1859) y casi inmediatamente suprimida (Ley Cortese de 6 de Diciembre de 1865) por razones económicas presupuestarias.

En Francia, fue durane el reinado de Enrique IV cuando se instauró la "abogacía de pobres" -mediante un decreto de 6 de Marzo de 1610-, norma en la que se ordenaba que en todos los Tribunales hubiera abogados para pobres, los cuales tendrían el deber de defender y patrocinar gratuitamente a todos los que cumplieran determinados requisitos, con una prohibición formal de recibir en cualquier forma compensación alguna, y con la única retribución que el soberano hubiese estimado conceder.

No es por tanto, tal "abogacía de pobres" el instituto del "advocatus deputatus et stipendiatus" del Derecho canónico, sino un encargo especial para la defensa de los pobres.

La "abogacía de pobres" pasó por diversas vicisitudes en Italia, llegando a ser 
asumida por los propios "Colegios de Abogados" que incluso, en algunas regiones, llegaron a establecer un día semanal de consultas gratuitas para los pobres que se presentaran (9).

En Francia, tras el reinado de Enrique IV llegó prácticamente a desaparecer la abogacía de pobres.

III.-4. También en España aparecen diversos intentos para institucionalizar una "abogacía de pobres" remunerada con fondos públicos, con un marcado carácter intervencionista del monarca y de control -lo que claramente se evidencia, como veremos después, por estimar "casos de corte" a quellos en los que estuvieran interesados pobres, huérfanos, etc.- coexistiendo en gran medida con el sistema que va a terminar también por predominar en España: atribución y correspondiente asunción de tal tarea por Letrados y Voceros que, designados de oficio, se ven obligados a hacerse cargo de ella.

Entre los datos histórico-normativos con los que contamos para hablar de una institucionalización de la defensa de los pobres, tenemos los pobres, tenemos los siguientes:

a) Ley de Adelantados mayores, en cuya L II se dice: "...et si por aventura duenna biuda, o huerfanos, o ome de orden, o cavallero que non aya sennor, e otro que sea reptado oviera pleyto fuer tan poderoso por que el adelantrado nol pueda dar otro tan poderoso por bocero, en adelantrado lo pueda ser por mandato del Rey" (10). Se encomienda a los Adelantados, entre otras, la defensa de viudas, huérfanos y "muy cuitados", debiéndose asimismo destacar que le competía, en general, la protección de los desvalidos, no solo económica sino socialmente.

b) Más tarde aparece la figura del Procurador-Fiscal, como oficial regio encargado de la defensa de los pobres. En la Ley de Estilo Li puede encontrarse un dato importante respecto al oficio de Promotor o Procurador-Fiscal, permitiendo afirmar la doble función que va a tener: Abogado de Rey en lo civil (en lo penal, el manarca no podía ser enjuiciado) y acusador público en lo penal.

La institucionalización de esta figura no se produce hasta las Cortes de Valladolid de 1312 y Ordenanzas Reales en que se fundaron las disposiciones de dicha reunión. Así se determinó: "Otrosi tengo por bien de haber un procurador que demande, razone é defienda por mio los mios pleytos, é los de las viudas pobres, é de los huerfanos pobres, é comunalmente de todos los huerfanos, que ovieren pleyto en la mi corte" (11).

A partir de este momento puede afirmarse la creación de tal oficio con carácter profesional y permanente, sin perjuicio del ejercicio eventual, total o parcial, de las mismas funciones por parte de individuos designados por el Rey para cada caso concreto y con seguridad entre dos Letrados de la Corte. Destaquemos también que tal oficio se actuará solamente ante los Tribunales de la Corte, es decir, en la cima de la jerarquía judicial, por tratarse de un ógano de la Administración central.

Prescindiendo ahora de que el Promotor fiscal se presenta como procurador de los pleitos del Rey, incluyendo aquellos casos de corte de caráter penal que, por una u otra razón, no sean perseguidos a instancia de parte (según se deduce de una generalización lícita de lo expuesto en la mencionada Ley II de las de Estilo), maticemos 
que aparece -al igual que sucedía con los Adelantados Mayores- como Abogado de los desvalidos social y económicamente, lo que en realidad es un "caso de corte" más (12).

Precisamente, como destacamos más arriba, la atribución de esta tarea (Abogado de los pobres) es uno de los datos que permite su conexión difusa con el Adelantado Mayor de la Corte y más claramente, con los Abogados de pobres, cargo este último creado quizás como alternativa parcial por Alfonso X en 1274. Así, en las Cortes de Zamora de 1274 se dice que: "en ninguno pleito pequenno, quello non razonen ellos, sinon si lo razonaren ayudando a los mesquinos pobres porque sean mas ayna librados. E por esto delos pobres, que tome el Rey dos Abogados sennalados, que sean omes buenos e que teman a Dios e sus almas, e que otro pleito ninguno non tengan sinon de los pobres, que les faga el Rey por quelo puedan facer. E esto se entiende delos mas pobres que a la corte vinieren, tales que no ayan que dar a los avogados" (13).

Con anterioridad, según nos dicen las Leyes de Estilo, cualquier Abogado tenía la obligación de actuar de oficio en caso de ser pobre el litigante. Así, en la L.XX: "El Abogado por su salario si aquel ha de dar salario no ha bienes de que lo pague, no gelo dara presso: vaya el ayuda que le fizo por el amor de Dios".

En principio quizás fuera factible presumir que ese oficio de "Abogado de pobres" que resucitará durante el siglo $\mathrm{XV}$, quedó sumido en el oficio de Procurador-Fiscal.

En la evolución posterior del Promotor (o Procurador) Fiscal, es destacable su duplicación (14) creándose dos procuradurías que respectivamente actuarian ante las dos instancias judiciales máximas: Audiencia y Consejo, adquiriendo una progresiva y cualitativa inportancia, dadas las atribuciones penales que se les reconoce (correlativas al desarrollo e implantación del sistema inquisitivo o de oficio propio de unas estructuras políticas más evolucionadas).

La importante reorganización de la Chancilleria llevada a cabo por Juan II en 1438, también afectó a la Procuraduría Real que actuaba ante dicho Tribunal (15), disponiéndose que en lo sucesivo quedara servida por dos personas que probablemente actuarían de forma alternativa o bien que especializarían seguramente sus funciones, uno en lo civil ante los Oidores y otro en lo penal ante los Alcaldes del Crimen, distribución que entendemos meramente funcional. Es más, y esto es lo importante para nosotros: se estableció la existencia de dos Abogados de pobres que, cnlazando con aquellos otros creados por Alfonso $\mathrm{X}$, tendrían a su cargo precisamente una de las misiones que desde su institucionalización se encomendó al Promotor-Fiscal; aunque carecemos de noticias en que apoyarnos, es de suponer que tales letrados debieron ser oficiales judiciales de la Administración castellana a nivel central desde muchos años antes, probablemente desde poco después de instituir la Audiencia.

Así, en las Ordenanzas Reales de Castilla, Lib. II, Tit. IV, Ley 1 se dice: "...Porende ordenamos y mandamos que en la nuestra Corte y Chancillería residan continuamente un Prelado, Presidente y quatro Oidores, y tres Alcaldes de la Carcel, y dos Procuradores Fiscales, y dos Abogados de los pobres...". 
c) Como ya se señaló más arriba, la defensa de pobres asumida por oficiales de la Administración central, mediante los Adelantados mayores en un primer momento y con posterioridad, por los Promotores-Fiscales, sin olvidar a los Abogados de pobres instaurados por Alfonso X y que vuelven a aparecer con Juan II en 1493, se simultaneó en gran medida con la designación de oficio por el Juez de Abogado y Vocero sque han de encargarse de la misma.

Destaquemos que la obligación de asumir tal mandato judicial se mantiene, pese a la consideración de que los pleitos de viudas, huérfanos y pobres constituyen "casos de corte"; así, en el Espéculo, I. 13, tit. 2, lib. IV, en la Ley de Estilo 91 ("...Estas son las cosas que fueron siempre usadas de librarse por la Corte del Rey: muerte segura, é muger forçada, é tregua quebrantada, salvo quebrantado, casa quemada... Y eso mismo los pleytos de viudad, é de huerfanos, é de cuytadas personas"). En I. 15, tit. 3, 3 Partida ("Contiendas e Pleytos y ha, sin aquellos que auemos dicho en la Ley ante desta, que son de tal natura, que segun Fuero de España, por razon dellos son tenudos los demandados de responder antel Rey, maguer non les demandassen primeramente por su fuero. E son estos: quebrantamiento de camino, o de tregua, riepto de muerte segura, muger forçada, ladron conoscido... o por razón de otro grand yerro de trayción, que quisiessen facer al Rey, o al Reyno; o por pleyto que demandasse huerfano, o ome pobre, o muy cuytado, contra algund poderoso, de que non podiesse tambien alcançar derecho por el fuero de la tierra. Ca sobre qualquier de estas razones, tenudo es el demandado de responder ante el Rey, do quier que lo emplazassen...".

En este sentido, HEVIA VOLAÑO nos dice que: Tiene también caso de corte el menor de veinte y cinco años huerfano de padre, y no basta ser lo uno sin lo otro... Tiene tambien caso de corte la viuda que viue honesta y recogidamente. Y lo mismo la muger que lo viuiere, aunque no se aya casado, no teniendo marido... Y tambien la muger casada que tiene el marido inutil, preso o desterrado, o de galeras, o en captiuerio, se tiene por viuda, para gozar (como goza) de priuilegio de caso de Corte, la viuda, menores, herfanos, pobres y personas miserables que tienen priuilegio de caso de Corte, le tienen como actores y reos, assi en demandando, como en defendiendo... Estas personas que tienen priuilegio de caso de Corte, nolo tien en ni gozan del en causas que sean de diez mil marauedies y de ay abaxo, sino dellos arriba... Ni tampoco gozan del dicho priuilegio en las causas sobre el aurer del Rey, o executiuas o criminales, o si se contesta la demanda ante el juez inferior sin declinar jurisdiction... (16).

En el mismo tenor, Alonso de VILLADIEGO, quien asimismo distingue entre "Casos de Corte" notorios o no. Los notorios son los de "...un Concejo contra otro; y los de Cabildos, y Monasterios, Hospitales... y contra los Grandes, y Señores de título, y contra los Oficiales y criados del Rey, puestos en oficio, y Dignidades supremas; qualquiera de estos casos se dice notorio, por ser cosa notoria, y basta alegarlos, sino que es necesario dar información sobre la calidad de ellos; como son el peyto del menor de veinte y cinco años y el de la muger viuda que viue honestamente...y lo mismo tiene Caso de Corte el pobre, y necesitado..." (17).

Con independencia del encargo real, la legislación histórica recoge con carácter 
general la necesidad de defensa gratuita del pobre, justificando la asunción de tal deber en el "amor de Dios", (Ley XX de la de Estilo).

Otro testimonio, si cabe aún más claro, se recoge en la $I, 6$, tít. 6 , de la $3^{\mathrm{a}}$ Partida, donde no sería aventurado hablar de "Abogado de Oficio"; en este caso, serán los "Juzgadores" quienes deban dar Abogado a las personas que lo soliciten ("Biuda, é huerfano, é otras personas cuytadas, han de seguir a las veces en juyzio sus pleitos. E porque aquellos con quien han de contender son poderosos, acaesce que non puedan fallar Abogado, que se atreua a razonar por ellos. Onde dezimos, que los Judgadores deuen dar Abogado, a cualquier de las personas sobredichas que gelo pidiere. E el Abogado, a quien el Juez lo mandare, deue razonar por ella por mesurado salario. E si por auentura fuesse tan cuytada persona, que non ouiesse de que lo pagar, deuele mandar el Juez que lo faga por amor de Dios, el Abogado es tenudo de lo facer..." (18).

d) Durante los siglos XIX y actual, por tanto desde la codificación precesal, la situación adquiere connotaciones específicas que no serán objeto de estudio.

El cumplimiento del encargo real de asumir la protección y defensa de los desvalidos o del mandato judicial de encargarse, de oficio y "por amor de Dios" de ella, viene asegurado por una Legislación que regula el veneficio de pobreza:

- En la Ley IV de las de los Adelantados Mayores ("...é que non tome nada de los pobres por quien razonarse, nin sea contra ellos, é si yo fallar que lo asi non guarda, haya sobre si las penas de los alcaldes...").

- En la Ley XIII del Espéculo ("... E si el alcalle mandare a alguno de los voceros que suelen tener cutianamente en la Corte, que tenga la voz de alguno, e non lo quisiere facer, devel alcalle defender por pena que no tena voz fasta un año en ningun pleyto, sino en aquellos que los pueda facer por derecho, segunt dice en el titulo que fabla de los voceros... E esto mismo dezimos que deven facer los adelantados de las merindades, e los alcalles, e los juezes de las villas, cada uno en aquellos logares en que an de judgar...").

- En las Cortes de Valladolid de 1312, 23 ("...e que non tome nada de los poures por quien rrazonares ninsea contra ellos. Et si yo fallar quelo assi non guarda, que aya sobre si la pena que es puesta sobre los dichos alcalles...").

En la Nueva Recop,. 1.28 tit.5, lib. 2 ("...Mandamos a los dichos nuestro Presidente, y Oidores, que se informen de los que litigan por pobres si los letrados siguen bien, y con diligencias sus causas, y los escriuanos, y si los otros oficiales de la nuestra Audiencia les lleua derechos; y los que halaren que tienen en ello culpa, los castigaren conforme a la justicia, y a los que de aqui delante excedieren en ello: y que prouean, como por culpa de los Letrados y procuradores de pobres, y otros Oficiales de la dicha nuestra Audiencia no se dilaten sus causas").

- También en la Nov. Recop. en el parágr. 83, de la 1,11, tit. 24, lib. 10 ("...que aque deba entenderse pobre de solemnidad, que se excusa de pagar derechos de Escribano, Abogado, Procurador, Solicitador, y Juez... y si se probare que algunos los hubiere llevado, pague cualquiera que lo hubiere hecho los derechos que tocan a los dichos sellos conel doblo; bastando para esta multa la deposición de un testigo, y la dé parte"). 
La legislación en la que ordena que no se dilaten las causas de los pobres está recogida:

- En la citada Ley 28, tit.5, lib.2 de la Nueva Recopilación.

- En la Ley 17, tit.2, lib.3 de la Nova Recopilación ("Mandamos, que en ver los pleitos conclusos guarden la orden y las leyes que se guarda en nuestras Audiencias; y que los sabados se vean pleitos de pobres y libertades, y Hospitales y Monasterios, e Iglesias, prefiriendo a los que mas razon huuiere...").

III.- 5. En cuanto a los requisitos para gozar de la defensa por encargo real o por decisión judicial:

1) Que se trate de viudas, huérfanos o pobres.

2) Respecto a los pobres, en la 1.20 , tit.23 de la $3^{\mathrm{a}}$ Partida, se equiparan a viudas, huérfanos, etc. y personas desamparadas los pobres que "non han valia de veinte marauedies".

3) Que se trate de personas socialmente desvalidas, y no únicamente desde el punto de vista económico. De este modo se encomienda su defensa a los Adelantados (L.II. cit.); El Juez designa Abogado cuando por ser el pleito con poderosos, no pueden encontrar a alguno que "se atreua a razonar por ellos" (Ley 6, tit. 6, Partida $3^{\circ}$ ).

4) Tratándose de pobres que lo acrediten:

- a). "Jurando serlo". Así, en L20, tit.XII, lib.1² (Nueva Recop., habien acordada en 1519): "Mandamos que las personas pobres, que agora, y de aqui en adelante estuvieren presos en las carceles, siendo despachados, y mandados librar en sus causas, jurando que son pobres y que no tienen de que pagar...".

- b). Y como se previene en la 1.25, tit.12, lib. $1^{9}$ de la Nueva Recop. -disposición que es la primera en la que hemos encontrado requisitos concretos para gozar del beneficio de pobreza, estando bajo la rúbrica "Con que información el pobre se ha de tener por pobre en las Audiencias para gozar de no pagar derechos": "...Mandamos, que quando alguno se dize pobre, para se escusar de pagar derechos á los oficiales de la Audiencias, que baste la información que de su pobreza truxere de fuera parte, dando un testigo en la Audiendia, que concluya: con tanto, que le tome el escriuano de la causa". Aunque recogida en este texto de 1567, en realidad proviene de una cédula dada por Carlos I en Monzón, en 1542. Esta Ley pasará posteriomente a la 1.7 , tit. 19, lib. $5^{\circ}$ de la Novísima Recopilación.

- c). En la Novísima Recopilación de 1805, aparte de las leyes señaladas al hablar de la Nueva Recop. y que pasan íntegramente, se puede apreciar el diferente tratamiento en la averiguación de la pobreza.

Los parágrafos 82,83 , y 84 de la 1.11 , tit.24, lib. 19 se refieren a los pobres. De todos ellos, el que más nos interesa en este momento es el 83, en el que se determina que "Para que no pueda hacer fraude en la averiguación y probanza de la pobreza, se declara, que aquel deba entenderse pobre solemnidad, que se excusa de pagar derechos de Escribano, Abogado, Procurador, Solicitador y Juez: bastando para este efecto la misma información que se hace, con arreglo á lo dispuesto por otras leyes, 
para probar la calidad de pobreza, con que en la información intervengan tres testigos, y se haga ante Escribano y Juez, que no han de levar derechos algunos...".

La posible explicación de la contradicción entre lo prevenido en la Nueva Recopilación y en la Novísima, puede estar en que, por un lado, la 1.7, tit.19, lib. $5^{\circ}$ de la Novísima recoge textualmente la Ley 25, tit. 12, lib. 1 de la Nueva; por otro lado, en que el señalado párrafo 83 tiene el origen en una Real Cédula de Carlos IV, de 23 de Julio de 1794, e instrucción inserta de 28 de Junio anterior.

La Ley 11 que contiene el meritado párrafo 83 dice: "Nuevas reglas sobre el uso del papel sellado en los autos, escrituras e instrumentos públicos", y en una pequeña "Exposición de motivos" aclara la necesidad de incrementar el precio del papel sellado, en base a la urgencia por conseguir fondos extraordinarios. Nada tiene pues de extraño que esa necesidad incremente también las garantías respecto de los requisitos para declarar (obtener) la pobreza. Téngase en cuenta asimismo que no se trata del único caso de duplicación de normas, con igual o diferente cotenido.

Alonso DE VILLADIEGO Y VASCUÑANA al tratar del "Pedimento de muger casada, pidiendo su dote al marido que va empobreciendo", señala la prueba testifical como medio de acreditamiento: "...Probarse la pobreza del marido en este caso, contra él, ó contra otro extraño, sobre la restitución de la dote, durante el matrimonio, no basta que el testigo diga: se que R. va empobreciendo, sino que conviene que diga: es manifiesto, público y notorio, que va empobreciendo... Y es de notar que si la pobreza del marido proviene de algún hecho que tenga la causa sucesiva, que en tal caso los vezinos son legitimos testigos, y mejores que los extraños, porque se presume que saben mejor los hechos del vezino... En resolución, como esta dicho, para probarse, que el marido no tiene bastante para el pago de la dote, basta y que conteste desto por opinión del vulgo, y de los vezinos" (19).

III.- 6. a) Designación de Abogado o "vocero" o asunción, en el momento histórico ya determinado, de tal tarea por Oficiales de la Administración Central.

b) Exención de derechos, que, a su vez, implica diferenciar:

- 1/ "Salarios" de Abogado-procurador (recogido tempranamente en la legislación, entre otras, en la mencionada Ley XX de las de Estilo)y

- 2/ de Juzgador y oficiales regios relacionados con el proceso (escribanos, relatores, etc), solo modernamente con carácter general se dictan normas en este sentido.

- 3/ otros que examinaremos a continuación (papel sellado, etc.).

La manifestación más antigua que hemos encontrado con respecto a la exención de derechos en beneficio de los pobres se remonta a las Cortes que Pedro III reúne en Barcelona en 1283. En la petición XI se contiene que a pobres y ódenes (religiosas) se les dan cartas de ejecución de justicia y las citaciones, sin que paguen nada por ello ("Item quod de carta simplicis justicie execucionis justicie et comissionis det quilibet singulares quinque solidos et non amplius, et universita decem solidos, et pro citacione dentur duo solidos; et littere huiusmodi dentru Episcopis prelatis et 
baronibus de factis eorum propiis, si presentes in Curia fuerint, et pauperibus et ordinibus qui proprium non habent sine precio. Et de littera seu carta alonfamenti, de qua consueverant dari quincuaginta solidos per mille in anno, dentur viginti solidos. Et ita secundum magis et minus volumus observari").

Estimamos que el texto últimamente citado está imbuido de profundas raíces del nuevo derecho que en esa época, y en Cataluña, no solo se ha "recibido" sino que se adopta y alcanza plena vigencia de hecho (20).

Como más arriba ya indicamos, la exoneración de gastos por defensa judicial del pobre se recoge tampranamente en la legislación; así, en el mencionado pasaje de las Cortes de Valladolid de 1312 con Fernando IV, el Procurador-Fiscal no debe llevar nada por su defensa y más aún, se contiene en la propia petición 23 una cláusula penal para los que contravengan tal prohibición. También en la Ley XX de las de Estilo.

En cuanto a la exención de gastos procesales, hasta la puclicación de la Nueva Recopilación de 1567, no puede hablarse de una cierta articulación de este principio. En la Nueva Recopilación son variadas las referencias a la "no toma de derechos" a los pobres, correspondiéndose con determinados preceptos más tarde recogidos en la Novísima Recopilación.

- En la Ley 28, tit. 5, lib. 2 (Nueva Recop.): "Que el Presidente y Oidores no se dilaten por culpa de Letrados y Procuradores los pleytos de los Pobres, y que no se les lleue derechos". Esta norma pasará a la Novísima Recopilación como 1.30, tit.1, lib. $5^{\circ}$.

- En la 1.28, tit. 8, lib. 2 de la Nueva Recop., en el fol. 117, $1^{\text {a }}$ col. "in fine", se recoge que "...a los pobres se les den los registros sin derechos...". Esta Ley no pasa a la Novísima.

- El Título XIII del lib. $1^{\circ}$ de la Nueva Recop. recoge de manera sucesiva cuatro importantes leyes en esta materia:

- Ley 20: "Que a los pobres presos, jurando serlo, no los detengan, ni les tomen los vestidos por razón de derechos". Estos derechos son los de "las justicias, y escribanos y carceleros..."; se especifica además que "ni se les tomen las capas, ni ropas, ni sayos, ni sayas, y mantos y otros vestidos que truxeren, y se les bueluan, si los huuieren dado en prendas de los dichos derechos, sin lleuarles cosa alguna por razon de los dichos derechos...". Se agrega además una cláusula penal "...y que el carcelero, o alguazil, o escriuano, o otra persona, que lo contrario hiziere, incurra en pena por cada vez un ducado para los pobres de tal carcel, y de suspensión del oficio que tuuiere por un mes. Y mandamos a las justicias, que tengan especial cuydado de haber si se cumple lo susodicho, y de executar las dichas penas en los que no complieran".

- Ley 21: "Que los condenados en setenas, pobres, no sean detenidos por los derechos, y costas, aunque otros paguen por ellos las setenas". Se aplican las penas de la Ley anterior (21).

- Ley 22: "Que a los pobres, executada en ellos pena corporal, no los bueluan a 
la carcel por derechos" (aludiendo a los derechos de las justicias, escriuanos y carcelero). También contiene esta norma para los transgresores (22).

- Ley 23: "Que los derechos de los oficiales, no los paguen los pobres, ni les compelan a que den fiador ni se paguen de las limosnas que les hizieren; que los oidores y las justicias castiguen, y executen las penas a lo que los lleuaren (23).

Todas estas leyes pasan correlativamente a la Novísima Recopilación de 1805, con los números 20 a 23 del tit. 38 , lib. 12 .

En la Ley 17, tit. 2, lib. 3, también de la Nueva Recopilación, se estatuye que los pleitos de los pobres se vean los sábados y que los que hubieren hechos "solemnidad", ni escribanos ni relatores les lleven derecho alguno, bajo pena del "quatrotanto" para la Cámara real.

La Ley 57, tit. 4, lib. 3ㅜㅗㅇ asimismo de la Nueva Recop., y también respecto de los pobres, acoge el mandato dirigido a los Alacaldes Mayores de los Adelantamientos para que "...hagan comprar camas para los presos pobres, y limpiarlas y renovarlas a sus tiempos...".

En los Capítulos de Corregidores -según recoge Alonso de VILLADIEGO- se les previene para que "...despachen primero, y con brevedad al pobre... y al huerfano, y a las personas miserables. y brevien los terminos maliciosos que las partes suelen pedir..." (24).

Asimismo, según prescribe la Nov. Recop., en su parágrafo $82,1.11$, tit. 24, lib. $10^{\circ}$ "A todos los pobres de solumnidad se les permite que en lo judicial usen del papel del sello quarto, con que mas que cuatro maravedies de cada pliego entero, y dos maravedies de cada medio pliego; y en lo que han de servir para esta efecto, se ha de poner la inscripción siguiente: "Para pobres de solemnidad": Porque no puedan servir para otra cosa".

Junto a tales "Beneficios" que implica el reconocimiento de la pobreza, puede destacarse, por el contrario, una serie de "limitaciones" entre las cuales destacan las siguientes respecto a ser parte como acusador y a ser testigo:

A.- Con respecto a la posibilidad de que el pobre pueda ser acusador:

- Ya PILLII MEDICINENSIS (en su "Summa de ordine iudiciorum") citando el D. 48. 2. 8: dice "Si sabemos quienes pueden acusar, entenderemos quienes no pueden hacerlo. En efecto, si impide que lo hagan, unos... D. 48. 2. 10" otros por su pobreza, como son los que tienen menos de 50 aúreos (25).

- En la 1.2, tit. 1, de la Séptima Partida, se ve notablemente disminuida para el pobre la posibilidad de ser parte de un procedimiento por cuanto expresamente se le prohíbe ser acusador "...si non ha la valia de cincuenta marauedies..." ("Acusar puede todo ome que non es defendido por las leyes deste nuestro libro. E aquellos que non puedan acusar, son estos: la muger e el moço que es menor de catorce años, e el alcalde, o merino... E aun dezimos, que aquel que ouiesse fechas dos acusaciones, non pueda facer la tercera, fasta que sean cabadas por jyzio las primeras. Otrosi dezimos, que ome que es muy pobre, que non ha la valia de cincuenta marauedies, non pueda facer acusación...". En idéntico sentido HEVIA VOLAÑO dice que "los prohibidos de ser acusadores son... el que es muy porbre..." (26). 
El origen de esta prohibición impuesta al pobre que tenga menos de cincuenta maravedíes, encuentra su antecedente en Digesto 48. 2. 10. (hermogeniano, 6: "iuris epitomarum", "...nonnulli propter paupertatem, ut sunt qui minusquam quinquaginta 'aureos' habent", como destacó la literatura jurídica intermedia.

Frente a tan radical prohibición de acusar, autores como Julio CLARO defienden que no obstante tal limitación no operará si es de fe y vida honesta y fiel y si se trata de perseguir "injurias propias" ("...quod si talis pauper est bonae et honestae fidei et vitae non suspectus propter paupertatem non repellitur ad accusando" (27). Asimismo, sigue diciendo Julio CLARO: "...si suam vel suorum iniuriam prosequatur" (28).

B.- Con respecto a la posibilidad de que el pobre pueda ser testigo, PILLII MEDICINENSIS (P. 3, pargrf. 8) dice:

"Illud nempe sciendum est diligenter in testibus, utrum sint locupletes vel egentes, et an mimiei ei, adversus quem producuntur, vel amici ei, pro quo inducuntur, ut Dig. e. t. $22,5.1 .3$ (pr); nam intimus amicus proferentis et valde inimicus eius, contra quem inducitur, omnimo repellitur; et sic intelligo legem illam et Cod. e. t. 4, 20, L. si quis, 17. ciertamente debe conocerse diligentemente este en los testigos, si son ricos o pobres, o si son enemigos de aquél contre el que son presentados, o amigos de aquél a favor del que deponen (como D. 22. 3. 52, pr; pues el íntimo amigo que le lleva, y el muy enemigo de aquél contra el que depone, deben ser rechazados completamente..." (23), añadiendo además el autor: "Propter paupertatem repellitur quis. Ut in Auth. t. e. \& 1. (Nov. 90 c. 1. \&. 1) Sed pauperem hic intelligo illum, qui habet minus quinquaginta aureis. arg. Dig. de accusat. 48, 2 1. nonnulli 10. Pauperes autem interdum admittuntur si sunt bonae famae, opinionis et idei; non enim tam facultatibus quam fide testis idoneus aestimari potest arg. Inst. de suspect. tut, 1, 26, \& ult. et in Auth. e. \&. 1 (Nov. 90. c. 1 \&1). Verum quandoque et egens et locuples repellitur, puta si lucri causa aliquid facile admiserint ut Dig. e. t. 22, 5, 1. 3 (pr.) Item testimonium, ut sic admittendum, care e debet suspicione, et propter personam, a qua fertur, quod sit honestae el bonae famae, item propter causam, puta quod nequegratiae, aut lucri, aut inimicitiae cause sit ut Dig. e. t. 22, 5. 10 1. 5. (pr.).

En Novell, 90 c. 1.1 (30). Pero además, aquí entiendo por pobre aquel que tiene menos de 50 aureos, (arg. en D. 48. 2. 10). En cambio, a veces son admitidos los pobres si son de buena fama, reputación y credibilidad; pero se les puede considerar testigos idóneos, no tanto por sus recursos sino por su credibilidad (Inst. 1. 26, 13) (Novell. 90, c. 1,1) Pero a veces el rico y el pobre son rechazados porque se piensa que pueden admitir fácilmente algo a causa de lucro (como D. 22. 5. 3). En todo caso, este autor (p. 3, \& 13 "De la credibilidad de los testigos") dice tajantemente que es más creíble el rico que el pobre ("...item magis diviti quam pauperi") (31).

En el mismo sentido se pronuncia TANCREDI BONONENSIS, afirmando en primer lugar: Prohibentur etiam pauperes a testimonio, tam iure fori, quam iure poli ut C. 2. q. 1. c. imprimis 7. (\&3), et I, prohibentur (c. 14) et in Auth de testil \& 4 (Nov. 90 c. 1) Et dicunt quidam, hoc obtinere in criminalibus causis dumpta at, et 
generaliter obtinere de quibuslibet pauperibus, qui minus quam quinquaginta aureos habent. Mili videtur hoc dictum esse de his pauperibus tantum, qui obtentu pecuniae praesumuntur supprimere veritatem; quoniam si testis est honestus ita quod nulla praesumptio sit contra eum, ut pro pecunia menfiatur, licet pauper cit, pauper sit, non est repellendus a testimonio; alioquin enim oporteret dici multos sanctos et viros religiosos et etiam ipsos apostolos a testimonio repellendos, que pauperes sunt nihil habentes", y concluyendo después que "Item rotius credendum est veidico quam mendaci emndato quam luxurioso, magis diviti quam pauperi" (32).

Con respecto a la posibilidad de que el pobre pueda ser testigo, en la Ley VIII, tit. VII, li. IV del Espéculo, se determina: "...E dezimos que los pobres de que dixiemos en la Ley ante desta, que non podrien testiguar, que por estos se deve á entender é non por otros, asi como aquellos que non an en su valia en mueble e en rayz de veynte mrs. arriba, con todo esto que son de mala vida. Mas si fuere conoscido por de buena vida, e que non aya sospecha contra el, que dixiese falso testimonio por aver nin por otra cosa, nol pueden desechar por esta razon que nos sea testigo". Asimismo, en la Ley 8, tit. XVI, de la $3^{\mathbf{a}}$ Partida: "Todo ome de buena fama e... puede ser testigo. E aquellos a quien es defendido, son estos...nin ome muy pobre, e vil...".

La literatura acogió también esta limitación para ser testigo, entre otros, AYLLON LAINEZ (33), FARINACCI, etc. Este último dice: "...quod inste testis est vilis pauper et abiectus quo causa criminalibus non recipitur secundum communem... Vbi enim cum paupertate testis concurrit etiam vilitas tunc non solumm non est idoneus testis sed etiam a testificando repellitur..." (34). Julio CLARO mantiene que para la mayoría de los autores, el pobre no puede ser testigo, aunque para algunos es una cuestión que queda al arbitrio judicial (35).

Se les reconoce a los pobres, muy cuitados y desvalidos, fuero especial, particularmente en las "alçadas". Que de las "alçadas" y de los otros pleitos que hayan de resolverse en la Corte juzge el Tey: "Biudas, o juerfanos, si ouieren alçadas, o otros pleytos, porque hayan de venir a la Corte del Rey, el los deue judgar... Esso mismo dezimos de los otros que son tan pobres, que non ha valia de veynte marauedies...Otrosi dezimos, que por si querella de alguno mandare el Rey a otro por su carta, que oya aquel pleyto de que le querellaron, o que le judgue; si alguna de las partes se agrauiare de su mandamiento, o de su jyzio, non se due alçat a otro ninguno, fueras al Rey que lo mando fazer" (Ley 20, tit. 23, Partida 3ä; en Nueva Recop., Ley 10, tit. 4, lib, 11).

III.- 7. Sobre la pobreza de las personas jurídicas. No solo gozan del beneficio de pobreza las personas físicas, sino que también se les reconoce este derecho a determinadas personas jurídicas. Así, en este sentido, los Reyes Católicos por Pragmática de 1502 y Felipe II en 1554 (sancionadas en la Novísima Recopilación, Ley 5, tit. 35, lib. 11), "Mandamos a los de nuestro Consejo y Oidores de las nuestras Audiencias, Alcaldes, Notarios de nuestra Casa y Corte y Chancillerías...Secretarios y Escribanos de nuestra Audiencias y otros qualiesquier juzgados, y otras qualesquier personas no consientan llevar ni lleven derechos algunos a los Monasterios de la Orden de San Francisco y de San Agustín, y Santo 
Domingo y del Carmen, que estan reformados en Observancia, de qualquier Orden que sean, de qualesquier mercedes y limosnas, ni privilegios, ni cartas, ni provisiones, ni procesos ni otros autos algunos; y los dichos nuestros Contadores ni Secretarios, ni Escribanos de Cámara y Escribanos de nuestras Audiencias ni otros oficiales, no los pidan ni lleven en manera alguna: y que los otros Monasterios de las otras Ordenes que estan reformados, o se reformaren de aqui adelante, que no paguen derechos algunos de las cartas, y provisiones y privilegios que sacaren, ni del sello ni del registro, estando en regular Observancia...".

Por decreto del Consejo de 14 de Agosto de 1782, con motivo de haber pretendido el General de la Orden de S. Juan de Dios, que "a consecuencia de lo declarado en esta Ley, se librase de provisión, para que en todos los Tribunales se ayudase a defendiese por pobres a las Casas de su Orden, sin exigirles derechos algunos; se denegó esta solicitud conformándose el Consejo con lo expuesto por su Fiscal, fundado en que, al tiempo de la promulgación de la Ley del año 1502, no tenían bienes los Monasterios reformados, y después, por el Concilio de Trento en el año 1563, se les habilitó para poder adquirirlos y tenerlos, como los tenían, cesando por consiguiente la concesión de ayudarlos y defenderlos por pobres, con la cesación del motivo de ella".

También, por Autos del Consejo de 14 de Septiembre de 1774 y 4 de Mayo de 1775 , en pleito seguido por los administradores del Hospital de Santa Cruz de Barcelona sobre la pertenencia de ciertos bienes, "enel qual se defendieron por pobres, y obtuvieron providencia definitiva a su favor, se mandó que de dichos bienes pagasen el relator y Escribano de Cámara sus respectivos derechos de relación y executoria".

Asimismo, por otro Auto del Consejo de 14 de Enero de 1792, "en pleyto seguido por el Hospital de pobres incurables de Córdova sobre la subsistencia de una vinculación hecha a su favor, en el cual se defendió por pobre conforme a lo dispuesto en dicha Ley (1.5, tit. 35, lib. 11, Novís. Recop.), y obtuvo executoria, se mandó que esta se despachase sin perjuicio de los derechos de ella pertenecientes a la Escribanía de Cámara".

Al igual que con los pleitos de pobres, en la Nueva Recopilación (1. 17, tit. 2, lib. 3), se previene que "...los sabados se vean pleitos de pobres y libertades, y hospitales y monasterios, e Iglesias".

IV.- 8. Aunque con clara inspiración en las fuentes iuscanonistas, como sucede en general, fruto de la recepción jurídica romano-canónica, en España cabe hablar históricamente de una gran preocupación sobre el tema. Tal preocupación cristalizó en institutos diferentes y en regulaciones diversas, según habrá podido apreciarse en la esquemática exposición realizada. De la misma, podría concluirse que, pese a las distintas fuentes (disposiciones normativas, opiniones doctrinales, decisiones de Cortes, etc.) de que nos hemos servido -en todo caso, decisivas a la hora de comprender la configuración histórica de la Justicia gratuita-, todas ellas han contribuido de manera decisiva junto a una "práctica forense" de la que esporádicamente se tienen noticias, a comformar una base bastante sólida expresiva de la importante y generalizada preocupación sobre el tema, base que sirvió de oportuno fundamento a 
la legislación decimonónica procesal, sobre todo a la Ley en Enjuiciamiento Criminal de 1872, compilación de 1879, Ley de Enjuiciamento Criminal de 1882 y Ley Enjuiciamiento Civil de 1881, en gran parte vigentes, sin perjuicio de las modificaciones introducidas en esta última por la Ley de 34/84 de 6 de Agosto.

\section{BIBLIOGRAFIA}

AYLLON LAINEZ, I. De Vtrariensis illustrationes sive additiones eruditissimae ad varias resolvtiones Antonii Gomezii, Lvgduni, sump Fratrum Anissoniorvm, \& Ioannis Posvel, 1626.

CALDARA, E y CAVAGNARI, C. Avvocatura dei poveri, en Digesto italiano, IV, 2, Torino, 1893-1899. También en Avvocatura dei poveri, en Novissimo Digesto italiano, I, 2, Torino 1958.

CAPPELLETTI, M. "Pobreza y Justicia", en Proceso, ideología y sociedad, Buenos Aires, 1974; y también en la edición italiana, "Povertá e Giustizia", en Giustizia e Societá, Milano, 1972.

CARRARA, F. Il passato, il presente e l'avenire degli avvocati in Italia, Lucca, 1894.

CLARI, J. Opera omnia, sive practica civilis atque criminalis, Lugdunim sumpt. Horatii Boissat \& G. Remevs, 1661.

DENTI, V. Processo civile e giustizia sociale, Milano, 1971.

FARINACII, P. Consilia, sive responsa arque decisiones causarum criminalium, Lvgdvni, sumpt. Horacii Cardon, 1607.

FIGUERUELO BURRIEZA, ANGELA El derecho a la tutela judicial efectiva, Madrid, 1990.

GONZALEZ PEREZ, J. El derecho a la tutela jurisdiccional, Madrid, 1984.

HEVIA VOLAÑO, I. Cvria Philippica, Valladolid, 1609.

LALINDE BADIA, J. Iniciación histórica al Derecho español, Barcelona, 1970.

OLIVA SANTOS, ANDRÉS DE LA, Sobre el derecho a la tutela jurisdiccional, Barcelona, 1980.

ORTIZ DE ZÚÑIGA, M. Biblioteca judicial o tratado original y metódico de la organización y atribuciones de los Juzgados de primera instancia de las Audiencias y del Tribunal Supremo de Justicia, Madrid, 1849, 3 tomos; del mismo, Práctica general forense, Madrid, Vda de Jordán e hijos, 1870, 3 tomos.

PEREZ DE LA CANAL, La Justicia en la Corte de Castilla durante los siglos XIII al XV, Historia, Instituciones, Documentos, Sevilla, 1975.

PILLIUS, TANCREDUS, GRATIA, Libri de iudiciorum ordine, Herausg, F. ch. Bergmann, Neudr, der Ausgabe, Goettingen, 1842, Aalen, 1965.

SERRANO ALBERCA, J.M., y otros, Comentarios a la Constitución, Madrid, 1980.

VILLADIEGO VASCUÑANA, A., Instrucción política y práctica judicial, Madrid, imp. Geronimo Roxo, 1729.

\section{NOTAS}

(1).- No entro lógicamente en un análisis de este Derecho a la tutela judicial efectiva, que está dando lugar a numerosos trabajos de investigación, principalmente por juristas, así, vid. entre otros muchos, los de SERRANO ALBERCA, J. María, "Comentario al artículo 24,1 de la C.E.", en Comentarios a la Constitución, dirigidos por Garrido Falla, Madrid, 1980, GOMEZ-FERRE MORANT, Rafael, "Derecho a la tutela judicial y posición jurídica peculiar de los poderes públi- 
cos", en Revista Española de Derecho Administrativo, 1982, núm 33, Abril-Junio, págs 183 y ss, OLIVA SANTOS, Andrés de la, Sobre el derecho a la tutela jurisdiccional, Barcelona, 1980, GONZALEZ PEREZ, Jesús, El derecho a la tutela jurisdiccional, Madrid, 1984, FIGUERUELO BURRIEZA, Angela, El dercho a la tutela judicial efectiva, Madrid, 1990, etc.

(2).- Sobre la doctrina del Tribunal Constitucional en tomo al derecho a la Justicia gratuita, entre otras muchas, es factible citar la sentada en su sentencia de 25 de Enero de 1983.

(3).- Sobre este instituto vid. CALDARA, E. y CAVAGNARI, C., Voz "Avvocatura dei poveri", en Digesto italiano, IV, 2, Torino, 1893-1899, esp.pp. 712 y ss, también Voz "Avvocatura dei poveri" en Novissimo Digesto italiano, I,2, Torino, 1958, pp 183 y ss.

(4).- Así, CAPPELLETTI, M., "Pobreza y Justicia", en Proceso, ideología y sociedad, Buenos Aires, 1974, p 156 y ss., edición italiana, "Povertá e Giustizia", en Giustizia e Societá, Milano, 1972 , p 237 y ss.

(5).- FERRARIS, "statu ecclesiastico", en Biblioteca canonica, Voz "Advocatus", n. 24-27, cit. en Novissimo Digesto italiano 1958, op. cit.

(6).- CAPPELLETTI, M. ops. ctis. respectivamente en pp 157 240-241.

(7).- Más ampliamente en DENTI, V., Processo civile e giustizia sociale, Milano, 1971, p. 137 y ss.

(8).- DENTI, V., Le ideologie del processo di fronte al problema sociale, en Processo civile e giustizia sociale, op. cit, $\mathrm{p} 22$.

(9).- Esto es gratamente comentado por CARRARA, F., Il passato, il presente e l'avvenire degli avvocati in Italia, Lucca, 1894, p. 5 y ss.

(10).- También, Leyes 19 y 22, tit 9, p.2 Proemio., Leyes 11 y 12, tit, lib 4 del Espéculo.

(11).- Cortes de Valladolid de 1312, 23, Cortes I p. 203, que plasmaron las Ordenanzas de 1310, ed. Benavides, en Memorias de D. Fernando IV de Castilla, vol II, doc DX p. 735; en la edición de las Cortes de Valladolid de 1312, p. 203 se dice: "...Otrossi tengo por bien de auer vn procurador que demande é rrazone é deffienda por mi los mios pleytos é los de las biudas pobres é de los verffanos... é que non tomen nada de los poures".

(12).- Como "caso de corte" es recogido por PEREZ DE LA CANAL, La Justicia en la Corte de Castilla durante los siglos XIII al XV, Historia, Instituciones, Documentos., Sevilla, 1975, p. 397-8.

(13).- Cortes de Zamora de 1274, 3 Cortes, I, p. 88.

(14).- Ordenanzas Reales de Castilla, II, 12, I. También Cortes de Briviesca de 1378, 30, Cortes, II, p. 389, esp. peticiones 18 a 31 y correspondientes respuestas.

(15).- Ordenanzas Reales de Castilla, II, 4, I.

(16).- HEVIA VOLAÑO, I, Cvria Philippica, Valladolid, imp. Iuan Godinez de Millis, 1609 , parág. 9, núms. 13 y ss, p. 143-44.

(17).- VILLADIEGO VASCUÑANA Y MONTOYA, A. Instrucción política y práctica judicial, Madrid, imp. Geronimo Roxo, 1729, fol. 26.

(18).- Como recogen ORTIZ DE ZUÑIGA Y HERRERA, Deberes y atribuciones de los Correjidores, Justicias y Ayuntamientos de España, IV, Madrid, 1832, p. 167-8, citando las Leyes 10 , tit. 6, Partida 3 y 13 y Ley 11 y s. del tit. 22, libro 11 de la Novísima, que "Según el juramento que presta todo abogado antes de recibir el tútulo, y lo que prescriben las leyes, tienen la obligación de defender las causas de los pobres de gracia, y sin retribución alguna, en los pueblos donde no hubiere letrados asalariados para este objeto, a menos que no los puedan defender por algún impedimento lejítimo: y tanto los abogados como los demás curiales deben encargarse de promover la justicia en las causas de oficio, trabajando en ellas sin interés alguno, cuando los reos carecen de facultades para satisfacerles sus honorarios, no solo en las causas contra paisanos, sino en las que se sigan contra militares" (en este último sentido, los autores mencionados citan Acuerdo del Consejo de la Guerra de 4 de Enero de 1828).

(19).- VILLADIEGO VASCUÑANA, A. Instrucción política y... (ver nota 17). 
(20).- En este sentido, tal vez pueda interpretarse como expresión de la adaptación producida en el derecho catalán y la elaboración doctrinal que se origina en Castilla, sin que se haya verificado el salto del tratamiento doctrinal a la incorporación a la legislación de las Cortes. Vid. a este tenor a LALINDE ABADI, J. Iniciación histórica al Derecho español, Barcelona, 1970, p. 810.

(21).- Ley 21 , tit. XII, lib. $1^{2}$ Nueva Recopilac.: "Porque acaece, que algunos presos son condenados en penas de setenas, $y$ defecto de no pagar en pena corporal, algunos parientes, $o$ amigos $o$ otras personas, pagan por ellos las dichas setenas, que haciendo juramento que son pobres, y que no tienen de que pagar las costas, y derechos de la justicia, y escriuanos, y carcelero, no sean detenidos por ello, y luego les suelten: y el que en contra lo susodicho viniere, incurra en las penas contenidas en la Ley precedente".

(22).- Ley 22, tit. XII, lib. $1^{2}$ Nueva Recop.: "Mandamos, que de aqui adelante, quando alguna persona pobre fuere condenado en pena corporal, siendo en ellas executada la pena, non los tornen por la dicha causa a la carcel; ni por razón de los derechos de las justicias, y escriuanos, y carcelero: y que luego donde se cabare la execucion, lo suelten libremente, si no huuiere otra causa porque deuan tornart a la carcel; y que a los dichos pobres, siendo condenados en pena de destierro, que queriendo salir a los cumplir, luego los suelten, ni los detengan por razon de los dichos derechos, lo qual cumplan las justicias y oficiales".

(23).- Ley 23, tit. XII, lib. $1^{\circ}$ Nueva Recop.: "Otrosi, porque acaesce que alguno de los dichos pobres son oficiales, y procuran que otro de su oficio se obligue a pagar las costas, y derechos por ellos, y de otra manera no los quieren soltar, y asimismo de lo que se les da por limosna para pagar sus condenaciones, quieren ser pagados de los dichos derechos: mandamos, que de aqui en adelante no se haga assi, ni apremien a los dichos pobres que den fiador, ni sean pagados de las dichas limosnas, sino constando que son pobres y no tienen otros bienes, no esten presos por razón de las costas, y derechos de las justicias, y de alguaziles..."

(24).- VILLADIEGO VASCUÑANAN, A., Instrucción política y práctica judicial, ver notas 17 y 19.

(25).- PILLII MEDICINENSIS, Summa de ordine iudiciorum, p. $3 \& 8$ ("De testibus") en Libri de iudiciorum ordine (PILLIUS, TANCREDUS, GRATIA), herausg. v. F. Ch. Bergmann, Neudr, der Ausg. Gottingen, 1842, Aalen, 1965, p. 64.

(26).- HEVIA VOLAÑO, I. Cvria philippica, cit. III parágrf. 8, p. 562.

(27).- CLARI, I., Opera omnia sive practica civilis atque criminalis, Lugduni, sumpt. Horatii Boissat et G. Remevs, 1661, n. 19, fol. 439.

(28).- CLARI, I., op. cit. quaestio XIV, n. 40, fol. 128.

(29).- PILLII MEDICINENSIS, op. cit. p. 64.

(30).- PILLII MEDICINENSIS, op. cit. p. 65.

(31).- PILLII MEDICINENSIS, op. cit. p. 72.

(32).- TANCREDI BONONENSIS, Ordo iudiciarius, p. 3, tit. 12, en Libri de iudiciorum ordine, op. cit. p. 225 y 246.

(33).- AYLLON LAINEZ, I. de, Vtrariensis illustrationes sive additiones ervditissimae ad varias Resolutions Antonii Gomezii, Lvgduni, sump. frates Anissoniorum \& Inoannis Posuel, 1626 , fols. 243 y ss.

(34).- FARINACII, P. Consilia, sive responsa atque decisiones causarum criminalium, Lvgduni, sumpt: Horatij Cardon, 1607, Consilium XXII, n. 27, folio 106.

(35).- CLARO, J. op. cit. quaestio XXIV, n. 11, folio 459. 